University of Nebraska - Lincoln

DigitalCommons@University of Nebraska - Lincoln

U.S. National Park Service Publications and

Papers

National Park Service

2010

\title{
Evaluation of Bear Rub Surveys to Monitor Grizzly Bear Population Trends
}

Jeffrey B. Stetz

University of Montana, jeff.stetz@gmail.com

Katherine C. Kendall

USGS-NRMSC Science Center, kkendall@usgs.gov

Christopher Servheen

University of Montana - Missoula, grizz@umontana.edu

Follow this and additional works at: https://digitalcommons.unl.edu/natlpark

Stetz, Jeffrey B.; Kendall, Katherine C.; and Servheen, Christopher, "Evaluation of Bear Rub Surveys to Monitor Grizzly Bear Population Trends" (2010). U.S. National Park Service Publications and Papers. 53. https://digitalcommons.unl.edu/natlpark/53

This Article is brought to you for free and open access by the National Park Service at DigitalCommons@University of Nebraska - Lincoln. It has been accepted for inclusion in U.S. National Park Service Publications and Papers by an authorized administrator of DigitalCommons@University of Nebraska - Lincoln. 


\title{
Evaluation of Bear Rub Surveys to Monitor Grizzly Bear Population Trends
}

\author{
JEFFREY B. STETZ, ${ }^{1}$ University of Montana Cooperative Ecosystem Studies Unit, Glacier Field Station, Glacier National Park, West Glacier, MT \\ 59936, USA \\ KATHERINE C. KENDALL, United States Geological Survey-Northern Rocky Mountain Science Center, Glacier Field Station, Glacier National Park, \\ West Glacier, MT 59936, USA \\ CHIRSTOPHER SERVHEEN, United States Fish and Wildlife Service, College of Forestry and Conservation, University of Montana, Missoula, MT \\ 59812, USA
}

\begin{abstract}
Wildlife managers need reliable estimates of population size, trend, and distribution to make informed decisions about how to recover at-risk populations, yet obtaining these estimates is costly and often imprecise. The grizzly bear (Ursus arctos) population in northwestern Montana, USA, has been managed for recovery since being listed under the United States Endangered Species Act in 1975, yet no rigorous data were available to evaluate the program's success. We used encounter data from 379 grizzly bears identified through bear rub surveys to parameterize a series of Pradel model simulations in Program MARK to assess the ability of noninvasive genetic sampling to estimate population growth rates. We evaluated model performance in terms of 1) power to detect gender-specific and population-wide declines in population abundance, 2) precision and relative bias of growth rate estimates, and 3) sampling effort required to achieve $80 \%$ power to detect a decline within 10 years. Simulations indicated that ecosystem-wide, annual bear rub surveys would exceed $80 \%$ power to detect a $3 \%$ annual decline within 6 years. Robust-design models with 2 simulated surveys per year provided precise and unbiased annual estimates of trend, abundance, and apparent survival. Designs incorporating one survey per year require less sampling effort but only yield trend and apparent survival estimates. Our results suggest that systematic, annual bear rub surveys may provide a viable complement or alternative to telemetrybased methods for monitoring trends in grizzly bear populations.
\end{abstract}

KEY WORDS bear rubs, grizzly bear, mark-recapture, Montana, noninvasive genetic sampling, Northern Continental Divide Ecosystem, Pradel model, trend monitoring, Ursus arctos.

Effective programs for monitoring wildlife populations should serve 2 primary purposes consistent with adaptive management: 1) provide periodic assessments of the status and trends of population metrics of concern, and 2) improve understanding of how populations respond to management actions (Pollock et al. 2002, Joseph et al. 2006, Nichols and Williams 2006). Effective monitoring programs must acquire the information needed to make management decisions in a useful time frame, as well as provide insight into the nature of the parameters being monitored and the factors impacting them to help predict the response of animal populations to management actions (Gibbs 2000, Nichols and Williams 2006). Such predictions are often imprecise and, even if a response to management is detectable, the time lag may be too long to change trajectory within an acceptable time frame. Imprecise or poorly selected metrics often fail to identify problems until either it is too late to prevent precipitous population declines or rescue would require extraordinary measures. Avoiding such scenarios through early detection of declines should be one of the primary objectives of any monitoring program, especially for small, isolated populations and for species with low reproductive rates such as grizzly bears (Ursus arctos; Abrams 2002).

Grizzly bears have been a federally listed threatened species in the contiguous United States since 1975. Until recently, monitoring of the Northern Continental Divide Ecosystem (NCDE) grizzly bear population in northwestern Montana consisted of opportunistic counts (sightings) of

\footnotetext{
${ }^{1}$ E-mail: jstetz@usgs.gov
}

females with cubs, distribution of females with young, and known, human-caused mortalities, a method that has proven to be problematic in the NCDE (Servheen et al. 1996, Kendall et al. 2009). These uncorrected indices usually assume that changes in raw counts reflect true changes in population abundance or distribution and not simply a change in detection rates, a condition that is difficult to assess (Williams et al. 2002). Consequently, it was understood that these measures were imprecise and that inferences about population status or trends based on them were limited (US Fish and Wildlife Service [USFWS] 1993, Mace 2005, Kendall et al. 2009).

In 2006, the state of Montana released a draft grizzly bear management plan stating that population trend information will guide management decisions (Dood et al. 2006). To address this need, Montana Department of Fish, Wildlife, and Parks initiated a trend-monitoring program that uses live capture and collaring to estimate vital rates for the NCDE grizzly bear population. This program focuses on female bears because this cohort drives population trend (Eberhardt et al. 1994, Garshelis et al. 2005, Mace 2005). The program aims to annually radiotrack $\geq 25$ independent female bears in perpetuity to estimate population trajectory, reproductive rates, cause-specific mortality, and unreported mortality rates. To maintain a sample of 25 radiocollared females, far more bears are captured and handled each year (i.e., males, dependent offspring, and black bears [ $U$. americanus]). For example, during 2004-2006, 97 grizzly bears were caught 111 times, only 45 of which were independent females (Mace and Chilton 2007). Live capture of bears is expensive, logistically difficult in remote areas, 
requires specialized training of field personnel, has inherent risk to both bears and trappers, requires aerial relocation of bears to monitor dependent offspring survival, and may be subject to intense scrutiny and potential moratoria on public lands. Although tracking the fate of individual bears is necessary to measure vital rates and may provide a better understanding of what drives population trend (e.g., causespecific mortality), noninvasive genetic sampling (NGS) represents a powerful complement, and potential alternative, to traditional methods of monitoring population trend.

In contrast to methods relying on live capture, NGS protocols permit study of populations without the need to handle or even see the study animals. Systematic collection of bear hair samples for genetic analysis has been used to estimate population density with high levels of precision, at large geographic scales in areas where live-trapping would have been difficult and costly, and where methods based on sightings have proven problematic (Boulanger et al. 2002; Kendall et al. 2008, 2009). Although application of NGS methods to study bear populations have primarily focused on estimating abundance (Woods et al. 1999, Boulanger et al. 2002, Dreher et al. 2007) or measuring population fragmentation (Proctor et al. 2002, 2005), their potential for long-term monitoring of population growth rates $(\lambda)$ and distribution has been recognized (Apps et al. 2005, Karamanlidis et al. 2007, Kendall et al. 2008).

Recently, 2 large-scale research projects in northwestern Montana, USA, estimated grizzly bear abundance employing 2 concurrent NGS methods (Kendall et al. 2008, 2009). In addition to the traditional grid of baited hair traps, hair samples were collected periodically from naturally occurring bear rubs during the Greater Glacier Area Bear DNA Project (Glacier Project) during 1998-2000 and the Northern Divide Grizzly Bear Project (Northern Divide Project) in 2004. Bears rub primarily on standing trees but they also rub on sign and fence posts, power poles, and a variety of other objects. In nonforested areas such as the Rocky Mountain Front in Montana, hair is also passively left by bears as they cross wire fences or brush against gates (Kendall et al. 2009). Bear rubs occur at varying densities along trails, forest roads, and power lines across a wide range of land management regimes throughout the NCDE and are known to exist in most, if not all, brown bear populations around the world (Green and Mattson 2003, Karamanlidis et al. 2007, Kendall et al. 2009). More than 55,000 hair samples were collected from baited traps and unbaited bear rubs during the Glacier and Northern Divide Projects, identifying 711 unique grizzly bears. Bear rub sampling increased the minimum number of bears detected by $22-24 \%$ each year and resulted in more precise abundance estimates than would have been possible with hair trap data alone (Boulanger et al. 2008a; Kendall et al. 2008, 2009).

Although abundance estimates remain the focus of most wildlife management and conservation plans (Nichols and Hines 2002, Schwartz et al. 2007), estimates of $\lambda$ are better suited to assess the health of a population. Our objectives were to evaluate the ability of mark-recapture modeling of

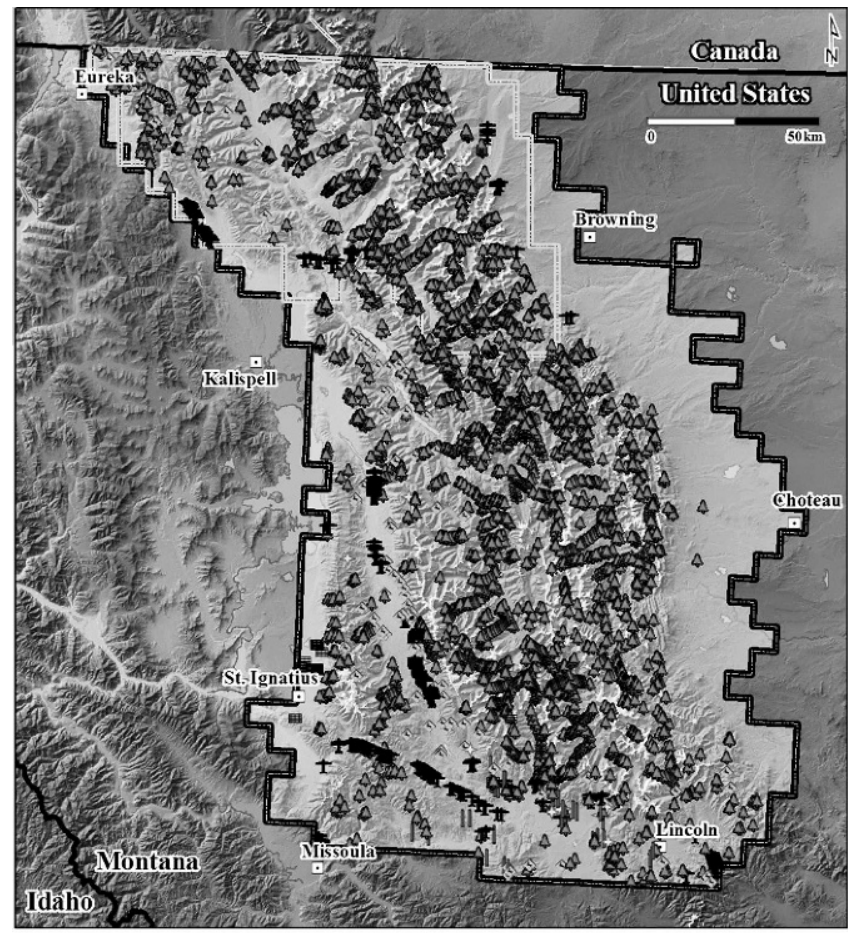

Bear rub type and count

A Tree $(4,070) \Leftrightarrow$ Sign post $(167) \equiv$ Fence $(79)$

I Power pole (330) I Fence post (72) $\diamond$ Other (77)

NDGBP study area 5 GGABDP study area

Figure 1. Map of the Greater Glacier Area Bear DNA Project (GGABDP) and Northern Divide Grizzly Bear Project (NDGBP) study areas, Montana, USA, and distribution of bear rubs surveyed by the Northern Divide Project during 15 June to 15 September, 2004.

genotype data obtained through periodic bear rub surveys to estimate population growth rates of grizzly bears in northwestern Montana, and to provide recommendations on optimal study design for long-term monitoring of this population.

\section{STUDY AREA}

The 31,410- $\mathrm{km}^{2}$ Northern Divide Project study area encompassed essentially all lands occupied by grizzly bears in the NCDE in northwest Montana, USA, in 2003-2004 (Fig. 1; Kendall et al. 2009). The Northern Divide Project study area extended from the United States-Canada border approximately $240 \mathrm{~km}$ to south of Montana Highway 200. The western boundary followed United States Highway 93 and the east shore of Flathead Lake. From the western boundary, the study area extended on average $125 \mathrm{~km}$ east onto the prairie beyond United States Highways 89 and 287. Lands within the NCDE were managed under numerous agencies, designations, and regimes. The study area included all of Glacier National Park, portions of 5 national forests (Flathead, Helena, Kootenai, Lewis and Clark, and Lolo), 5 designated wilderness areas (Bob Marshall, Great Bear, Mission Mountains, Rattlesnake, and Scapegoat), the Blackfeet Nation and Confederated Salish and Kootenai reservations, Swan River, Stillwater, and Coal Creek state forests, large tracts of corporate timber land, hundreds of private land owners, and numerous other 
governmental and nongovernmental entities. Approximately $75 \%$ of the study area was mountainous and $35 \%$ was roadless.

The study area was bisected longitudinally by the Continental Divide, which served as a geo-climatic boundary affecting weather patterns and, consequently, vegetation composition. Areas west of the Divide had a lower average elevation and, due to maritime influence, received considerably more precipitation than areas east of the Divide. Lands east of the Divide were under a continental climate and received more solar radiation and frequent high, sustained winds. Most of the eastern-most portion of the study area is in the prairie biome, dominated by open grassland. The $8,000-\mathrm{km}^{2}$ Glacier Project study area (Kendall et al. 2008) coincided with the northern quarter of the Northern Divide Project study area and had considerably higher bear density than the remainder of the NCDE (Kendall et al. 2008, 2009).

\section{METHODS}

\section{Field Methods}

Bear rub sampling occurred on approximately $50 \%$ and $80 \%$ of the Glacier Project and Northern Divide Project study areas, respectively. Surveys were essentially limited to Glacier National Park during the 3 years of the Glacier Project. For the Northern Divide Project, we omitted areas along the Rocky Mountain Front due to insufficient personnel and scarcity of bear rubs (Fig. 1). The forested portion of the Northern Divide Project study area contained $>7,000 \mathrm{~km}$ of maintained trails plus many thousands of kilometers of forest roads. We found bear rubs along power lines, fence lines, and other travel routes frequented by bears throughout the study area. Although bear rubs occurred away from travel routes, we limited our efforts to such routes to ensure that surveys were repeatable and efficient.

For both projects, we trained each crew member in recognition of bear rubs, such as discoloration of tree bark and animal paths leading to a rub. Approximately $70 \%$ of identified rubs in the Northern Divide Project had $330-\mathrm{cm}$ pieces of 12-gauge, 4-pronged barbed wire nailed to the rubbed surface to facilitate hair collection, obtain larger hair samples with more follicles, and reduce the rate of samples containing hair from multiple bears. On the remainder of the bear rubs, those that showed signs of being impacted by passing pack-stock, we used double-stranded wire (i.e., no barbs) to avoid damaging panniers. The separated ends of the wire and the staple contact points were found in field trials to be nearly as effective as barbed wire at capturing hair samples (A. Macleod and J. Stetz, University of Montana, unpublished data). We tagged each rub with a unique number, obtained coordinates with a Global Positioning System unit, and recorded information about the rub (e.g., type [tree, post, etc.], tree species, distance from trail). When identifying bear rubs, we attempted to have $\geq 2$ crews survey each route because crews' ability to identify rubs improved with experience.

We surveyed each rub periodically during the sampling period, with sampling effort varying across sessions and years. To account for this variation, we developed a measure of bear rub sampling effort, defined as the cumulative number of days between successive hair collections for all rubs sampled per time period. Upon each collection visit to designated bear rubs, we inspected each barb for hair. We placed all hair from each barb into a uniquely numbered paper envelope and recorded the date, personnel, and tag number. To prevent contamination among surveys, we passed a flame under the barbs to ensure that no stray hair fragments remained after we collected the sample. We collected only hair on barbs (i.e., we did not collect hairs on tree bark) to make sampling effort comparable across rubs, to minimize time required for collection, and to ensure that we could determine the period of time in which the sample was deposited. To ensure that we did not analyze hairs left prior to our sampling, we included only those genotypes from hair samples where the period of deposition was known. We entered all data into a relational database with numerous integrated error-checking tools, as well as extensive postanalysis quality-control measures (Kendall et al. 2008, 2009).

\section{Genetic Methods}

We stored hair samples on silica desiccant at room temperature until analyzed at a laboratory specializing in noninvasively collected samples, following protocols outlined in Woods et al. (1999), Paetkau (2003), and Roon et al. (2005). We determined species, individual identity, and gender of bears through analysis of nuclear DNA extracted from hair follicles; we analyzed all samples with $\geq 1$ guard hair follicle or 5 under-fur hairs, and we used up to 10 guard hairs plus under-fur when available. We used the G10J microsatellite marker for species assignment; we genotyped at all 7 markers used for individual identification of any sample with an ambiguous species result and analyzed it with assignment tests to verify species (Paetkau et al. 1995, Kendall et al. 2009). We used 7 microsatellite loci to define unique individuals: G10J, G1A, G10B, G10C, G10L, G10M, and G10P (Paetkau et al. 1995). We assigned gender using the amelogenin marker (Ennis and Gallagher 1994), the accuracy of which we verified through submission of samples from bears whose gender was known through management actions (Kendall et al. 2009).

We rejected samples whose genotypes contained weak, missing, or suspect data and used selective reanalysis of similar or suspicious genotypes to detect and remove erroneous data. We genotyped all individuals at least twice using $\geq 2$ geographically distant samples when possible or a single sample when necessary. We submitted 863 blind samples (748 concurrently with field samples plus 115 intentionally mixed samples following field sample analysis) to estimate error rates and verify consistency of genotypes across lab technicians over the duration of analyses. We verified all individuals identified with our 7-marker system with an independent set of 9 additional loci (G10C, G10L, CXX110, CXX20, Mu50, Mu59, G10U, Mu23, and G10X; Kendall et al. 2009). 
Table 1. Parameter values and simulation models used to evaluate the power of bear rub surveys to detect a $3 \%$ annual decline in the Northern Continental Divide Ecosystem, Montana, USA, grizzly bear population.

\begin{tabular}{|c|c|c|c|c|c|c|c|c|c|c|c|}
\hline \multirow{2}{*}{$\frac{\text { Design type }}{1 \text { Session (nonrobust design) }}$} & \multirow[t]{2}{*}{ Model notation } & \multicolumn{10}{|c|}{ Capture $P$ used in simulations ${ }^{a}$} \\
\hline & & & & M & & & & & $\mathrm{F}$ & & \\
\hline Gender-specific & $\varphi(\mathrm{g}) p(\mathrm{~g}) \lambda(\mathrm{g})$ & & & 0.53 & & & & & 0.26 & & \\
\hline Pooled genders & $\varphi(\mathrm{g}) p(\mathrm{~g}) \lambda()$. & & & 0.53 & & & & & 0.26 & & \\
\hline & & \multicolumn{10}{|c|}{ Session } \\
\hline 2 Session (robust-design) & & & M1 & & M2 & & & $\mathrm{F} 1$ & & $\mathrm{~F} 2$ & \\
\hline Gender-specific & $\varphi(\mathrm{g}) p(\mathrm{~g}+\mathrm{t}) \lambda(\mathrm{g})$ & & 0.37 & & 0.36 & & & 0.13 & & 0.19 & \\
\hline Pooled genders & $\varphi(\mathrm{g}) p(\mathrm{~g}+\mathrm{t}) \lambda()$. & & 0.37 & & 0.36 & & & 0.13 & & 0.19 & \\
\hline 5 Session (robust-design) & & M1 & M2 & M3 & M4 & M5 & F1 & $\mathrm{F} 2$ & F3 & $\mathrm{F} 4$ & F5 \\
\hline Gender-specific & $\varphi(\mathrm{g}) p(\mathrm{~g}+\mathrm{t}) \lambda(\mathrm{g})$ & 0.23 & 0.23 & 0.17 & 0.21 & 0.17 & 0.04 & 0.07 & 0.07 & 0.11 & 0.08 \\
\hline Pooled genders & $\varphi(\mathrm{g}) p(\mathrm{~g}+\mathrm{t}) \lambda()$. & 0.23 & 0.23 & 0.17 & 0.21 & 0.17 & 0.04 & 0.07 & 0.07 & 0.11 & 0.08 \\
\hline
\end{tabular}

\section{Simulation Methods}

We conducted simulations based on empirically derived capture probabilities to estimate the power to detect a declining population with bear rub detection data. We used the simulation module in Program MARK (v.5.1, build 2600, < http://warnercnr.colostate.edu/ gwhite/mark/mark. htm>, accessed 10 Mar 2008; White and Burnham 1999, White 2008), which allows users to input relevant parameters (e.g., abundance, capture probabilities) to generate simulated populations, sample them, and analyze the mark-recapture data. For all simulations, we assumed $\lambda$ $=0.97$, where the population declines monotonically at $3 \% /$ year, resulting in a $26 \%$ decline after 10 years. This rate of decline would be considered rapid enough to warrant management intervention, but slight enough to demand a powerful monitoring method to detect. This simple scenario of no inter-annual variation in growth rates is unlikely in real populations; however, the Pradel (1996) model generates annual estimates of $\lambda$, not simply an average across all years of sampling. Assuming other factors are not at play (e.g., changing the area sampled), performance of the Pradel model in terms of bias and precision should not be substantially impacted by the variation in population growth rates typical of grizzly bears. We used gender-specific capture probabilities to generate all simulated data sets, from which we evaluated both gender-specific and gender-pooled $\lambda$ estimates.

Parameter values. - We obtained parameter values for use in mixture model simulations from the most supported model from the 2004 Northern Divide Project abundanceestimate model set as determined by the lowest Akaike's Information Criterion value adjusted for small sample size (Kendall et al. 2009). To estimate grizzly bear abundance in the NCDE, Kendall et al. (2009) used HugginsPledger closed mark-recapture models, which used a mixture of 2 capture probability distributions to model heterogeneity of one capture probability distribution (Pledger 2000). These models provided estimates of gender-specific mixture probabilities, as well as genderand session-specific capture probability estimates for bear rub data.
Nonmixture model simulations used capture probabilities derived as simple ratios of the number of bears detected in bear rub sampling in the relevant sample period to total population abundance estimates (i.e., $\hat{p}_{i}=n_{i} / \hat{N}$ ) from Kendall et al. (2009; Table 1). For robust-design models, where multiple sampling events are conducted each year (referred to as secondary occasions), capture probabilities were allowed to vary by gender and across secondary occasions to accommodate time variation in capture probabilities typical of bear rub data sets. We set recapture probabilities equal to capture probabilities because we expected no behavioral response within or across years (Boulanger et al. 2008b; Kendall et al. 2008, 2009). Nonrobust models simulated one encounter each year; therefore, we held capture probabilities constant across years. We assumed capture probabilities to be independent for all animals based on our knowledge of variable detection rates for members of family groups in bear rub data (Kendall et al. 2009).

Values of apparent survival were $(\varphi)$ approximations based on recent grizzly bear literature and considered appropriate for the NCDE population (Mace and Waller 1998, Garshelis et al. 2005). For all simulations, we set male $\varphi$ to 0.87 and female $\varphi$ to 0.92 (Table 1 ).

Simulation models. - To identify the most appropriate sampling design for monitoring trends in abundance with bear-rub surveys, we evaluated scenarios for gender-pooled and gender-specific estimates based on 1, 2, and 5 annual sampling occasions. We used 3 general formulations of the Pradel temporal symmetry model (Pradel 1996) in simulations performed in Program MARK (White and Burnham 1999). The most complex simulations attempted to model heterogeneity of capture probabilities using robust-design Huggins-Pledger mixture models (Huggins 1991, Kendall et al. 1997, Pledger 2000). In addition to estimates of the realized rate of population change $\left(\lambda_{i}=E\left[N_{i+1} / N_{i}\right]\right)$, the robust design produces abundance estimates as a derived parameter. We also used robust-design simulations in a nonmixture framework, which provided the same categories of parameter estimates (i.e., $\lambda$, $\varphi$, and $N$ ) but considered only one capture probability distribution for all individuals within 
Table 2. Bear rub sampling results in the Greater Glacier Area Bear DNA Project (1998-2000) and Northern Divide Grizzly Bear Project (2004) Montana, USA. We included in simulations and this table only data from surveys during 15 June to 15 September, and only those samples for which the time period of hair deposition was known.

\begin{tabular}{|c|c|c|c|c|c|c|c|c|c|}
\hline \multirow[b]{3}{*}{ Yr } & \multirow{3}{*}{$\begin{array}{l}\text { No. rubs } \\
\text { surveyed }\end{array}$} & & & \multirow{2}{*}{\multicolumn{2}{|c|}{ No. samples genotyped }} & \multicolumn{4}{|c|}{ No. grizzly bears identified } \\
\hline & & \multicolumn{2}{|c|}{ Rub sampling effort $\left(\mathrm{RSE}^{\mathrm{a}}\right)$} & & & \multicolumn{2}{|c|}{ Session 1} & \multicolumn{2}{|c|}{ Session 2} \\
\hline & & Session 1 & Session 2 & Session 1 & Session 2 & M & $\mathbf{F}$ & M & $\mathbf{F}$ \\
\hline 1998 & 576 & 6,252 & 16,920 & 52 & 96 & 17 & 11 & 26 & 11 \\
\hline 1999 & 740 & 28,710 & 28,297 & 309 & 148 & 59 & 26 & 40 & 25 \\
\hline 2000 & 790 & 24,004 & 33,809 & 235 & 168 & 49 & 14 & 41 & 30 \\
\hline 2004 & 4,795 & 172,121 & 146,357 & 1,026 & 865 & 110 & 60 & 106 & 88 \\
\hline
\end{tabular}

${ }^{a}$ RSE $=$ the cumulative no. of days between successive hair collections summed over all bear rubs sampled per time period. For example: if we surveyed 2,000 rubs in a session and 30 days elapsed since the previous survey, RSE would equal 60,000.

a group for each secondary occasion. Finally, we evaluated nonrobust, nonmixture formulations of the Pradel model, which collapsed all detections of each individual into one event within each year. We evaluated all models in terms of power to detect a specified change in abundance, percent relative bias, confidence interval coverage $(\mathrm{CIC})$, and an index of precision based on the coefficient of variation of $\lambda$. We defined power to detect a declining population as the percentage of simulation runs where the upper $95 \%$ confidence interval on $\hat{\lambda}$ was $<1$. Percent relative bias (PRB) was the difference between the estimated parameter value and truth (i.e., the value we used to generate the simulated data sets; $\mathrm{PRB}=[($ estimate - truth $) /$ truth $] \times$ $100 \%)$. We evaluated robust-design models with regard to bias, confidence interval coverage, and coefficient of variation of abundance estimates. We ran all simulations for $\geq 500$ realizations.

\section{Monitoring Program Design}

We explored several monitoring program designs from several perspectives. First, we estimated the number of years of annual sampling required to achieve $80 \%$ power to detect a declining population given capture probabilities achieved in the Northern Divide Project bear rub sampling effort. Next, we estimated the amount of sampling effort required to detect a declining population within 10 years with $\geq 80 \%$ power for 4 basic sampling designs. To estimate amount of sampling effort required, we again considered genderspecific and gender-pooled models with 1 and 2 sampling occasions/year (nonrobust and robust Pradel formulations). We also evaluated abundance estimates derived from the robust-design models for precision, confidence interval coverage, and bias, given the sampling effort required to meet the monitoring objective.

We used data collected during 4 years of bear rub surveys in the NCDE in a nonlinear (logarithmic) regression to estimate the number of individual grizzly bears that could reasonably be expected to be identified given a specified amount of sampling effort. We iteratively manipulated capture probabilities in each of the 4 simulation-model scenarios to the lowest possible values that still achieved $80 \%$ power to detect a declining population in 10 years. We then entered these hypothesized capture probabilities into the regression to estimate the amount of sampling effort required to detect the desired number of bears. We performed regressions for both robust and nonrobust sampling designs to estimate effort required to meet multiple management priorities. As with the previous simulations, we set male and female apparent survival to 0.87 and 0.92 , respectively, with initial population sizes based on the results of Kendall et al. (2009). We ran each simulation scenario for $\geq 500$ realizations.

\section{RESULTS}

\section{Field Sampling}

Rub tree sampling effort varied by year in the number of rubs surveyed, frequency of survey, and geographic distribution (Table 2; Fig. 1). From 15 June to 15 September 2004, the period from which we derived simulation parameter values, we surveyed 4,795 unique bear rubs 18,021 times. The average interval between visits was $17.8(\mathrm{SD}=9.1)$ days. We collected 12,564 hair samples from bear rubs, for an average of 0.697 samples/visit. We used results from the Glacier Project (1998-2000; Table 2) only in regression analyses to estimate the amount of effort required to obtain a desired capture probability. Details of Glacier Project sampling effort and results can be found in Kendall et al. (2008).

\section{Genetic Analyses}

Approximately $30 \%$ of the samples collected at bear rubs during the Northern Divide Project contained too few follicles to be analyzed, $40 \%$ were from black bears, and $14 \%$ failed at various stages in the analysis. We could not obtain individual genotypes from samples with hair from $>1$ individual; however, only $0.8 \%(n=92)$ of samples were mixed. We successfully genotyped 1,891 (15.1\%) grizzly bear hair samples at 7 microsatellite loci, from which we identified 155 unique male genotypes and 120 unique female genotypes. Individual genotypes were replicated, on average, in 9.1 ( $\mathrm{SD}=15.9)$ samples for males and 4.5 (SD = 3.4) samples for females.

Mean observed heterozygosity for the 7 markers used for individual identification was 0.73 . For the complete Kendall et al. (2009) data set of 563 unique grizzly bears, we estimated the probability that 2 randomly drawn individuals $\left(P_{\mathrm{ID}}\right)$ or full siblings $\left(P_{\mathrm{SIB}}\right)$ would share the same genotype at $9 \times 10^{-8}$ and $1.7 \times 10^{-3}$, respectively. All individuals differed at $\geq 3$ loci when we considered all markers, and each genotype from the supplemental 9 markers identified 

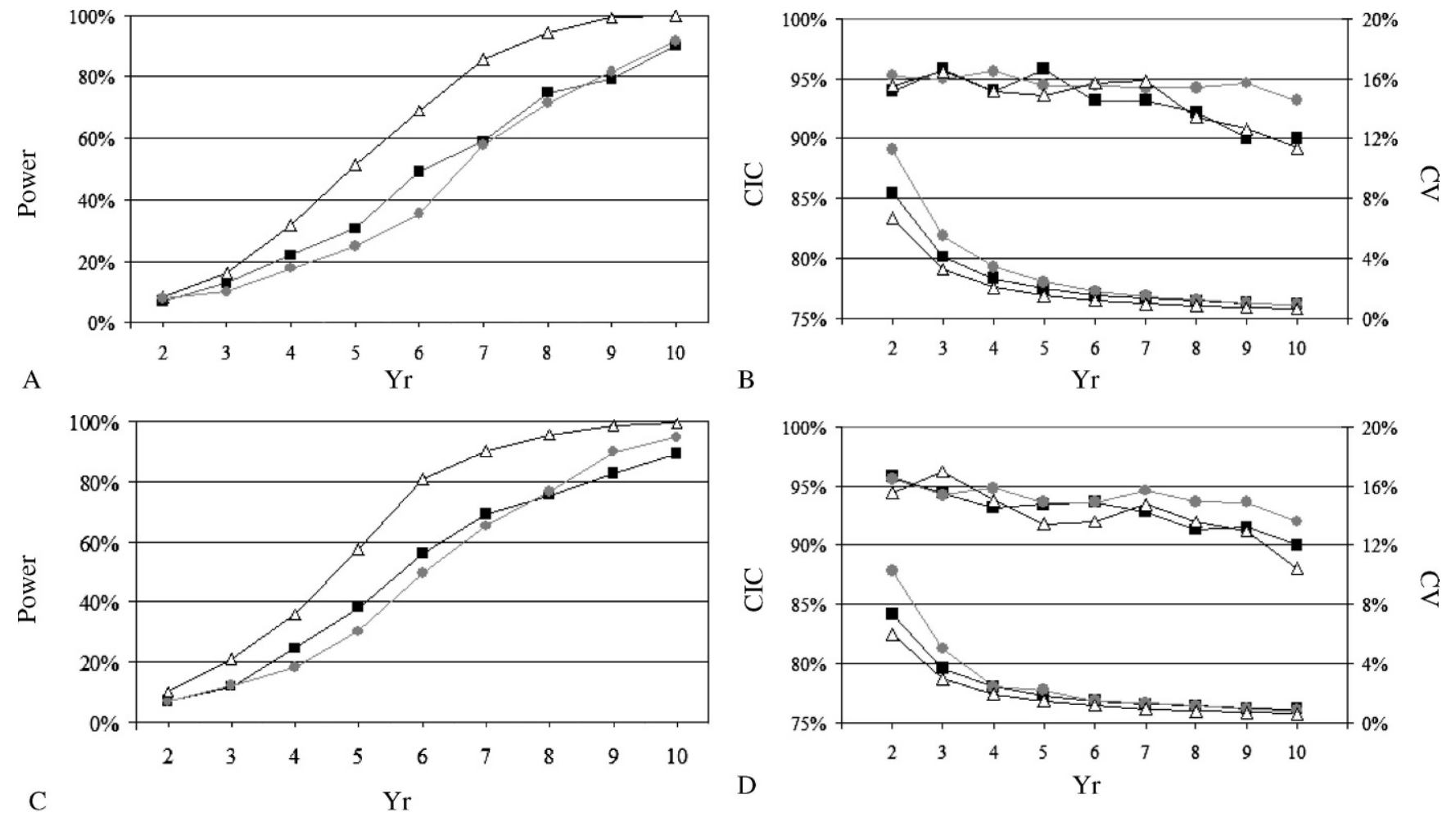

\section{$\rightarrow-\mathrm{M} \quad-\mathrm{F} \quad-\quad-$ Pooled}

Figure 2. Power, coefficient of variation, and confidence interval coverage (CIC) of bear rub surveys to detect a $3 \%$ annual decline in the Northern Continental Divide Ecosystem, Montana, USA, grizzly bear population. (A and B): one sampling occasion per year (nonrobust-design model). (C and D): Two sampling occasions per year (robust-design model). The bottom set of points (B and D) reflect coefficient of variation estimates with values given on the secondary y-axis. Parameter values used in simulations are provided in Table 1.

the same individual as the primary set of 7 markers. Of the 653 blind samples that yielded a complete genotype, 100\% matched the reference genotype, giving an estimated error rate prior to correction of $<0.15 \%(1 / 653)$ for 7 -locus genotypes. Further details on marker power, genotyping success rates, error rates, and blind samples can be found in Kendall et al. (2009).

\section{Simulations}

Single annual survey design.-We first evaluated nonrobust models with 1 sampling occasion/year. We tested both gender-pooled and gender-specific models for their power to detect a $3 \%$ annual decline in abundance and evaluated bias and precision of $\lambda$ estimates. For both approaches, percent relative bias of $\hat{\lambda}$ never exceeded $0.3 \%$ and remained $<0.1 \%$ by year 7 . Power curves resembled those of robust-design models (Fig. 2). Power exceeded 80\% for gender-pooled models by year 7 , whereas gender-specific models required 9 years. Precision of $\lambda$ estimates was essentially identical to the robust design, with a coefficient of variation $<6 \%$ in year 3 and continued improvement through year 10. Generally, CIC for nonrobust models followed the pattern seen with robust-design models; male and gender-pooled estimates declined to $90 \%$ in year 9 , whereas female CIC remained near nominal levels for all 10 years (Fig. 2).
Two secondary sampling occasions design.-Within this subset of simulations, we considered relative performance of gender-specific versus gender-pooled $\lambda$ estimates with a robust-design Pradel model based on 2 secondary occasions. As predicted, higher capture probabilities or more years of sampling were required to achieve adequate power to detect a change in gender-specific abundance than for genderpooled models (Fig. 2). Based on our empirically derived capture probabilities, power for gender-specific estimates improved nearly linearly with time, but did not exceed $80 \%$ until year 9 for both males and females. Conversely, gender-pooled models exceeded $80 \%$ power in only 6 years, the least amount of time required for any model. Percent relative bias in $\hat{\lambda}$ rarely exceeded $0.6 \%$ in either formulation and was $<0.05 \%$ in year 10 . Precision in $\hat{\lambda}$ improved rapidly for both gender-pooled and gender-specific models, converging at a coefficient of variation of $<6 \%$ by year 3 , and continuing to decline asymptotically through year 10 . Confidence interval coverage remained $>90 \%$ for genderpooled and gender-specific models through year 9, dropping slightly in year 10 for male and gender-pooled estimates. However, female CIC remained $>92 \%$ for all 10 years (Fig. 2).

We also evaluated the robust-design models for their ability to provide annual abundance estimates. Because underlying capture probabilities were the same regardless of 
Table 3. Description of models and parameter values we used to predict bear rub sampling effort required to exceed $80 \%$ power to detect $\lambda=0.97$ within 10 years for the grizzly bear population in the Northern Continental Divide Ecosystem, Montana, USA. ${ }^{\mathrm{a}}$ All model outputs are for year 10 of simulations.

\begin{tabular}{|c|c|c|c|c|c|c|c|c|c|c|c|c|c|c|}
\hline Model type & \multicolumn{4}{|c|}{ Capture $P$ used in simulations } & \multicolumn{2}{|c|}{ Power (\%) } & \multicolumn{2}{|c|}{$\operatorname{CV}(\lambda ; \%)$} & \multicolumn{2}{|c|}{$\mathrm{CV}(\hat{N})$} & \multicolumn{2}{|c|}{$\%$ relative bias } & \multicolumn{2}{|c|}{$\begin{array}{l}\text { Estimated } \\
\text { RSE }^{\mathbf{b}}\end{array}$} \\
\hline $\begin{array}{l}1 \text { Session (nonrobust- } \\
\text { design) }\end{array}$ & \multicolumn{2}{|c|}{$\mathrm{M}$} & \multicolumn{2}{|c|}{$\mathrm{F}$} & $\mathrm{M}$ & $\mathrm{F}$ & $\mathrm{M}$ & $\mathrm{F}$ & & & & & & \\
\hline $\begin{array}{l}\text { Gender-specific } \\
\text { Pooled genders }\end{array}$ & \multicolumn{2}{|c|}{0.53} & \multicolumn{2}{|c|}{0.26} & \multicolumn{2}{|c|}{84.4} & 1.0 & 1.1 & & & & & \multicolumn{2}{|c|}{$\begin{array}{r}165 \\
60\end{array}$} \\
\hline $\begin{array}{l}2 \text { Sessions (robust- } \\
\text { design) }\end{array}$ & $\mathrm{S} 1$ & $\mathrm{~S} 2$ & $\mathrm{~S} 1$ & S2 & M & $\mathrm{F}$ & M & $\mathrm{F}$ & M & $\mathrm{F}$ & M & $\mathrm{F}$ & S1 & S2 \\
\hline $\begin{array}{l}\text { Gender-specific } \\
\text { Pooled genders }\end{array}$ & $\begin{array}{l}0.37 \\
0.37\end{array}$ & $\begin{array}{l}0.36 \\
0.36\end{array}$ & $\begin{array}{l}0.13 \\
0.13\end{array}$ & $\begin{array}{l}0.19 \\
0.19\end{array}$ & 83.6 & 83.2 & 1.0 & 1.1 & $\begin{array}{l}7.9 \\
9.7\end{array}$ & $\begin{array}{l}12.1 \\
15.4\end{array}$ & $\begin{array}{l}3.2 \\
2.9\end{array}$ & $\begin{array}{l}3.0 \\
4.0\end{array}$ & $\begin{array}{l}40 \\
65\end{array}$ & $\begin{array}{l}50 \\
65\end{array}$ \\
\hline
\end{tabular}

${ }^{a}$ Parameter definitions: $\lambda=$ population growth rate; $\varphi=$ apparent survival. We used $\varphi_{\text {males }}=0.87$, $\varphi_{\text {females }}=0.92$, and $\lambda=0.97$ for all models, with recapture probabilities set equal to capture probabilities $(c=p)$ for robust-design models. True population sizes: $\mathrm{M}=294, \mathrm{~F}=470$.

${ }^{\mathrm{b}}$ We defined rub sampling effort (RSE) as cumulative no. of days between successive hair collections summed over all bear rubs sampled per time period (in thousands). We summed RSE for nonrobust designs for the entire sampling period each yr; we summed robust-design effort for each of 2 secondary occasions/yr.

how we parameterized the model for $\hat{\lambda}$, model performance with respect to $\hat{N}$ was essentially identical for all models (e.g., no paired annual estimates differed by $>1.4 \%$ among models). By pooling detections into only 2 secondary occasions, we avoided the sparse-data problems that we encountered with the 5 session mixture model approach (below). Pooling data also reduces heterogeneity in capture probabilities, which is difficult to model with sparse data (Boulanger et al. 2008a). Robust-design Pradel models were consistently positively biased for $\hat{N}$; however, bias remained between $1.5 \%$ and $4 \%$ for both genders for all 10 years. Standard errors of $\hat{N}$ declined by approximately $1.5-2 \% /$ year for both genders. However, because the simulated population was declining at $3 \%$ year, the net result was a slightly increasing coefficient of variation on $\hat{N}$, although even at year 10, the coefficient of variation for $\hat{N}$ remained $<9 \%$ for females and $<6 \%$ for males (Table 3). Confidence interval coverage declined more dramatically for males than females, reaching $72.6 \%$ and $89.8 \%$, respectively, at year 10 .

Five secondary sampling occasions design.-We first attempted simulations with Pradel robust mixture models based on 5 secondary occasions; however, sparse data, especially among female grizzly bears, resulted in unacceptable performance of the models. The Huggins-Pledger models used to derive abundance estimated that $78 \%$ of females had capture probabilities of $0.02-0.05$ for the 5 secondary occasions considered, which resulted in estimates of apparent survival $(\varphi)$ for females to be biased by $-15 \%$ after 10 years (i.e., with simulated $\varphi=0.92$, the model estimated $\varphi=0.78)$. Further, CIC on $\hat{N}$ was extremely poor for both genders, and approached zero for females due to substantial negative bias in abundance estimates. Although estimates of power to detect a change in abundance appeared high, the inability to satisfy data requirements for other parameters in this model precluded further consideration.

We next considered 5 secondary-occasion, nonmixture, robust-design Pradel models. These models had the same structure as the 2 secondary-occasions scenario; however, capture probabilities used in the simulations were reduced as a result of parsing detections into more occasions (Table 1 ). Power, bias, and precision of $\hat{\lambda}$ were essentially identical to the 2 secondary-occasion scenario, requiring 6 years for gender-pooled models to exceed $80 \%$ and 9 years for gender-specific. Confidence interval coverage on $\hat{\lambda}$ remained near $95 \%$ through year 6 , with gender-pooled and male CIC dropping to near $90 \%$ for years $7-10$; coefficient of variation on $\hat{\lambda}$ was $<4 \%$ by year 4 as with the other scenarios. The biggest distinction between performance of 5 and 2 secondary-occasion models was with confidence interval coverage on $\hat{N}$, which declined to $61 \%$ by year 10 for males with 5 occasions; female CIC remained $>90 \%$ for all years. Coefficient of variation for $\hat{N}$ remained $<4 \%$ and percent relative bias for $\hat{N}$ was $<6 \%$ for males and $<9 \%$ for females across all years.

Predicting sampling effort required to detect $\lambda=0.97$ within 10 years. - Our second objective was to estimate the amount of bear rub sampling effort required to detect a $3 \%$ annual decline in the NCDE grizzly bear population within 10 years with $\geq 80 \%$ power. Given the slightly poorer performance of the 5 secondary-occasion robust-design model, we limited this stage of the analysis to the nonrobust and 2 secondary-occasion robust-design models. The nonrobust, gender-pooled model required the lowest annual sampling effort to detect a declining population (Table 3). Notably, the gender-specific robust design required the second lowest amount of sampling effort to attain the desired power to detect a decline and would provide the greatest amount of information of the models considered in our analysis. Modeling the genders separately allowed the robust-design model to perform better, and resulted in $21 \%$ less effort than the gender-pooled design to attain adequate power with nearly identical precision.

\section{DISCUSSION}

Our simulations with the Pradel temporal symmetry models in Program MARK suggest that annual surveys of bear rubs have excellent potential to provide unbiased and precise gender-specific estimates of $\lambda$ for the NCDE grizzly bear population. This $\lambda$ differs from that of asymptotic projection 
matrices in that it includes all population processes, including emigration and immigration, not simply births and deaths. Further, unlike projection matrix approaches, the realized $\lambda$ from the Pradel model does not assume that the population has static vital rates or is at stable stage distribution (Nichols and Hines 2002), conditions that are unlikely to exist in the NCDE grizzly bear population.

Use of mark-recapture methods to estimate $\lambda$ have increased in recent years and appear especially well-suited to noninvasively derived encounter data. For example, Boulanger et al. (2004a) used DNA-based detections with the Pradel (1996) temporal symmetry model to investigate the relationship between salmon (Oncorbynchus nerka) availability and grizzly bear numbers in 3 sampling areas in British Columbia, Canada. Compared to using helicopters to count individual bears, Boulanger et al. (2004a) found that mark-recapture methods yielded improved precision of demographic estimates and a better understanding of how changing environmental conditions affect population trends. Sandercock and Beissenger (2002) directly compared $\lambda$ estimates derived from the Pradel model to those of asymptotic projection matrices and ratios of population counts and found estimates to be in general agreement, but the Pradel model had greater precision. Similarly, a study of a hunted black bear population in Arkansas, USA, found the Pradel model to be a reliable alternative to other, more costly methods to estimate population growth rates (Clark and Eastridge 2006). However, Barker et al. (2002) advised that a clear distinction between the realized $\lambda$ estimates of the Pradel model and asymptotic expectations of projection matrices must be made, and predictions based on retrospective markrecapture data should be made cautiously.

It also should be emphasized that estimates generated by the Pradel model are only applicable to the cohorts from which the encounter histories are obtained. Kendall et al. (2009) matched genotypes from handled bears to field samples to determine that individuals of all sex-age classes were detected with hair-trap and bear rub sampling combined. Because their sample of cub and yearlings was small $(n=15)$, more information is needed to properly estimate detection rates of these cohorts at bear rubs. The effects of this heterogeneity in capture probabilities can be minimized with the use of appropriate models (Otis et al. 1978; Pledger 2000; Boulanger et al. 2004b, 2008b; Kendall et al. 2009). For example, Huggins-Pledger closed mixture models have been used to improve estimates in the presence of undefined heterogeneity in bear rub data (Kendall et al. 2009). Further, Pradel model estimates of $\lambda$ have been found to be robust to moderately heterogeneous capture probabilities, such as those found in bear rub data (Hines and Nichols 2002). And although behavioral responses, especially permanent ones, can bias $\lambda$ estimates (Hines and Nichols 2002), no such response has been detected in 3 separate analyses of bear rub data (Boulanger et al. 2008a; Kendall et al. 2008, 2009). Proper model development, including use of temporal, group, and individual covariates, should result in even better performance of Pradel models than we found in these simple simulations (Boulanger et al. 2008a). It may also be possible to geographically parse rubtree detections to analyze population processes at a finer resolution, potentially correlating parameter changes with changes in landscape characteristics. Due to the limited sample sizes of most known-fate studies, finer resolution estimates are rarely possible with projection matrix methods, which typically yield one $\lambda$ estimate for an entire population.

As is common with bear NGS data sets, bear rub encounter data contain heterogeneity variation in capture probabilities. We accounted for this heterogeneity most effectively by using robust-design, gender-specific models, which make use of more of the available data. Although pooling data from an entire sampling season and obtaining gender-pooled $\lambda$ estimates resulted in slightly improved precision, robust-design models yield the greatest amount of information about the population by producing not only gender-specific $\lambda$ and $\varphi$ estimates, but abundance estimates as well. Pradel model estimates of $\varphi$ incorporate both true survival and emigration. Therefore, in populations that are essentially geographically closed, the Pradel model provides approximate estimates of true survival. However, we found that with low capture probabilities or few sampling occasions (e.g., $p \leq 0.05 ; \leq 5$ secondary occasions) estimates of $\varphi$ appear to be substantially negatively biased. The only other substantial bias (i.e., $>5 \%$ ) of any of the parameters we examined occurred with $\varphi$ and $p$ estimates with nonrobust models with $<3$ years' data. In all simulations, bias levels returned to $<5 \%$ by year 4 , which indicates that estimates from the first few years of a monitoring program must be interpreted with caution for nonrobust models. Robust-design models did not display this behavior, and bias levels remained $<5 \%$ for all parameter estimates.

An important assumption in mark-recapture analyses is independence of detections for animals in the sampled population; violating this assumption results in overdispersion of multinomial variances and underestimation of variance (Boulanger et al. 2008b). Kendall et al. (2009) reported empirical evidence for at least partial independence in captures for bears detected in bear rub sampling based on known family groups. Further, unlike closed population models, overdispersion can be estimated for Pradel models using a bootstrap approach based on the Cormack-JollySeber model (Franklin et al. 2004).

Annually fluctuating population growth rates may mask overall net declining (or increasing) abundance. Simulations suggested that additional years' data or increased capture probabilities would be required to achieve the same degree of power to detect a declining population under such a scenario. For example, with $\lambda$ alternating between 0.94 and 1.01 annually, which results in the same net reduction in abundance after 10 years as a monotonic $3 \%$ annual decline, 2 additional years' data are required to achieve $80 \%$ power given the same capture probabilities. Estimates of precision, confidence interval coverage, and abundance estimates for robust-design models were all similar to simulations with a constant $\lambda$ value. Also, the ability to detect positive growth 
rates is clearly important to managers. Simulations with $\lambda=$ 1.03 required 9 years to exceed $80 \%$ to detect an increasing population for both robust- and nonrobust-design models. Precision increased rapidly; however, confidence interval coverage on $\lambda$ and abundance estimates was poorer than scenarios of a declining population. The power of bear rub surveys to detect trends under variable or positive growth rates adds confidence to their application for long-term monitoring in real-world conditions.

Regressions of bear rub sampling effort against the number of bears detected had high correlation coefficients (only the first secondary-occasion female regression $\left[R^{2}=\right.$ 0.87 ] was $<0.96)$ and seemed reasonable given our knowledge of bear rub surveys. However, we regard these predictions as rough approximations intended for exploring general survey design in this population. We believe our measure of sampling effort adequately reflects the ability of bear rubs to detect bears at large spatial and temporal scales, in part because this measure has been overwhelmingly supported as a temporal covariate in abundance estimation models in both the Glacier and Northern Divide Projects (Boulanger et al. 2008a; Kendall et al. 2008, 2009). However, simply increasing the number of bear rubs surveyed without allowing adequate time for hair to accumulate (e.g., 15-30 days) will not result in increased detections. Another important design issue is that changes in sampling design or study area size can confound Pradel model estimates. For example, increasing the spatial extent of sampling will appear as an increase in population abundance as more individuals become available for detection (Franklin 2001, Barker et al. 2002). To avoid these effects, we recommend that a greater investment be made in the initial year of a monitoring project to establish as many rubs as possible over the geographic area of interest and that the sampling design remain stable over the course of any multiyear project.

Based on our experiences conducting bear rub surveys throughout this region, we estimated that a dedicated staff of approximately 12 technicians could establish and survey a sufficient number of bear rubs in this $>32,000-\mathrm{km}^{2}$ area to obtain precise estimates (e.g., $\mathrm{CV} \leq 6 \%$ ) within 3 years under the conditions we explored. In total, such a project would require approximately 5 full-time equivalent employees, compared to the approximately 4 full-time equivalent employees currently required to trap and collar bears for a telemetry-based trend-monitoring project in the same population (R. Mace, Montana Department of Fish, Wildlife, and Parks, personal communication), and $>60$ full-time equivalent employees for intensive grid-based hair trapping as in Kendall et al. (2009). Our estimates should be interpreted with caution because differences between populations are inevitable and will impact sampling requirements and, therefore, labor and other costs as well.

Unlike telemetry-based studies, bear rub surveys require little specialized training or equipment (e.g., collars, drug delivery devices), require no tracking flights, and can rely in large part on existing agency staff and other forms of in-kind labor (e.g., park rangers, student groups). Bear rub surveys can be limited to maintained routes (e.g., trails and powerpole lines) eliminating the need for helicopter and off-trail travel, which are often used in other types of studies. As such, surveys can be performed with no more risk of injury (to bears or people) than would be expected on any hike in bear country. Bear rub surveys do not require the production, transportation, and application of lure because rubbing is a natural behavior of bears. Mace et al. (1994) noted that annual and seasonal variation in food availability had dramatic effects on success at baited, remotely triggered camera sets, resulting in wide confidence intervals in their population estimates. Harris (1984) reported extremely low bear visitation rates while using a number of scent baits in multiple study areas, including some areas with high bear density. There is also evidence that capture probabilities at baited live-capture and hair traps are lower for bears that have been previously live-captured. This behavioral response results in greater heterogeneity of capture probabilities and is difficult to model without knowledge of which bears have been live-captured (Crosbie and Manly 1985, Boulanger et al. 2008b, Kendall et al. 2009).

The only substantial cost to conducting bear rub surveys beyond labor is genetic analyses of hair samples. Bear rub surveys in this population in 2004 collected nearly 13,000 hair samples (Kendall et al. 2009). However, the number of samples actually analyzed may be greatly reduced by subsampling and screening to eliminate poor-quality samples in the early stages of genetic analysis (Paetkau 2003). With 2 complete surveys per year, we estimated that approximately 3,300 hair samples would be considered for genetic analysis, with $<1,000$ yielding a complete grizzly bear genotype. More severe subsampling is possible, although the risk of failing to detect bears with lower capture probabilities will increase proportionally.

Numerous other noninvasive sampling methods have been developed that may prove to be adequate for monitoring growth rates for other populations and species. For example, Beier et al. (2005) devised a single-use hair grabber to be deployed along bear trails leading to salmon feeding streams. This concept offers the advantage of minimizing the risk of mixed samples in areas of high bear density, but it has a tendency to collect samples from nontarget species such as deer (Odocoileus spp.) and would not be suitable for areas of human use (Beier et al. 2005). Also, with recent improvements in fecal genotyping methods (e.g., Bellemain and Taberlet 2004, Luikart et al. 2008), scat collection has emerged as a viable sampling method for numerous species. Although sampling design issues will have to be addressed for other species and populations, novel methods such as bear rub surveys may offer many advantages over traditional baited or live-capture-based methods.

\section{MANAGEMENT IMPLICATIONS}

Noninvasive genetic sampling studies have provided managers with detailed information on grizzly bear populations over large and complex landscapes. We present a new approach to population monitoring that has advantages over both traditional forms of NGS and telemetry-based 
projection matrix methods. Bear rub surveys represent an efficient, safe, flexible, and noninvasive means to rapidly produce unbiased and precise estimates of population growth rates, abundance, apparent survival, and potentially other useful parameters such as relative density and genetic population structure. If rubs are surveyed $\geq 2-3$ times/year, collapsing detections into 2-3 secondary occasions for use in robust-design Pradel models absorbs much of the heterogeneity common in NGS studies, while providing greater information about the population and allowing a more flexible sampling design. As stated in the United States Fish and Wildlife Service's Grizzly Bear Recovery Plan, "The optimum monitoring system should ... not require continuous capture and handling of animals ... or highly trained and specialized personnel whose time is solely devoted to grizzly bear monitoring" (USFWS 1993:19). Our study demonstrates the potential for bear rub surveys to meet these expectations while providing data relevant to managing populations of difficult-to-study species such as grizzly bears. However, pilot studies should be conducted for other populations to ensure adequate representation and detection rates prior to development of a monitoring program based on these or similar methods.

\section{ACKNOWLEDGMENTS}

We thank G. White and J. Boulanger for assistance with concept and simulation development. D. Paetkau and D. Roon oversaw all genetic analyses. F. Allendorf, J. Beston, P. Krausman, A. Macleod, S. Miller, S. Mills, D. Patterson, O. Rhodes, M. Sawaya, G. White, and 2 anonymous reviewers provided helpful comments on earlier drafts of this paper. We thank the hundreds of employees and volunteers who collected hair samples under difficult field conditions, entered reams of data, and processed thousands of hair samples. We also thank the following agencies that provided data and substantial logistical and in-kind support: Blackfeet Nation; Confederated Salish and Kootenai Tribes; Montana Department of Fish, Wildlife, and Parks; Montana Department of Natural Resources and Conservation; National Park Service; Northwest Connections; United States Bureau of Land Management; Untied States Fish and Wildlife Service; and the University of Montana. Financial support was provided by the United States Geological Survey and United States Forest Service.

\section{LITERATURE CITED}

Abrams, P. A. 2002. Will small population size warn us of impending extinction? The American Naturalist 160:293-305.

Apps, C., J. Boulanger, and M. Proctor. 2005. Grizzly bear population monitoring in the central Rocky and Columbia mountains: a feasibility assessment. Prepared for Parks Canada; Mount Revelstoke and Glacier National Parks, Revelstoke, British Columbia; and Banff, Yoho and Kootenay National Parks, Lake Louise, Alberta. Aspen Wildlife Research, Calgary, Alberta, Canada.

Barker, R., E. Cooch, and C. Schwarz. 2002. Discussion comments on: 'Approaches for the direct estimation of $\mathrm{K}$ and demographic contributions to K using capture-recapture data'. Journal of Applied Statistics 29:569-572.

Beier, L. R., S. B. Lewis, R. W. Flynnn, G. Pendleton, and T. V. Schumacher. 2005. From the field: a single-catch snare to collect brown bear hair for genetic mark-recapture studies. Wildlife Society Bulletin 33:766-773.

Bellemain, E., and P. Taberlet. 2004. Improved noninvasive genotyping method: application to brown bear (Ursus arctos) faeces. Molecular Ecology Notes 4:519-522.

Boulanger, J., S. Himmer, and C. Swan. 2004a. Monitoring of grizzly bear population trends and demography using DNA mark-recapture methods in the Owikeno Lake area of British Columbia. Canadian Journal of Zoology 82:1267-1277.

Boulanger, J., K. C. Kendall, J. B. Stetz, D. A. Roon, L. P. Waits, and D. Paetkau. 2008a. Multiple data sources improve DNA-based markrecapture population estimates of grizzly bears. Ecological Applications 18:577-589.

Boulanger, J., G. Stenhouse, and R. Munro. 2004b. Sources of heterogeneity bias when DNA mark-recapture sampling methods are applied to grizzly bear (Ursus arctos) populations. Journal of Mammalogy 85:618624.

Boulanger, J., G. C. White, B. N. McLellan, J. Woods, M. Proctor, and S. Himmer. 2002. A meta-analysis of grizzly bear DNA mark-recapture projects in British Columbia, Canada. Ursus 13:137-152.

Boulanger, J., G. C. White, M. Proctor, G. Stenhouse, G. Machutchon, and S. Himmer. 2008b. Use of occupancy models to estimate the influence of previous live captures on DNA-based detection probabilities of grizzly bears. Journal of Wildlife Management 72:589-595.

Clark, J. D., and R. Eastridge. 2006. Growth and sustainability of black bears at White River National Wildlife Refuge, Arkansas. Journal of Wildlife Management 70:1094-1101.

Crosbie, S. F., and B. F. J. Manly. 1985. Parsimonious modelling of capture-mark-recapture studies. Biometrics 41:385-398.

Dood, A. R., S. J. Atkinson, and V. Boccadori. 2006. Grizzly bear management plan for western Montana: final programmatic environmental impact statement 2006-2016. Montana Fish, Wildlife \& Parks, Helena, USA.

Dreher, B. P., S. R. Winterstein, K. T. Scribner, P. M. Lukacs, D. R. Etter, G. J. M. Rosa, V. A. Lopez, S. Libants, and K. B. Filcek. 2007. Noninvasive estimation of black bear abundance incorporating genotyping errors and harvested bear. Journal of Wildlife Management 71:26842693.

Eberhardt, L. L., B. M. Blanchard, and Knight R. R. 1994. Population trend of the Yellowstone grizzly bear as estimated from reproductive and survival rate. Canadian Journal of Zoology 72:360-363.

Ennis, S., and T. F. Gallagher. 1994. PCR-based sex determination assay in cattle based on the bovine Amelogenin locus. Animal Genetics 25:425427.

Franklin, A. B. 2001. Exploring ecological relationships in survival and estimating rates of population change using Program Mark. Pages 350356 in R. Field, R. J. Warren, H. Pkarma, and P. R. Sievert, editors. Wildlife, land, and people: priorities for the 21st century. Proceedings of the Second International Wildlife Management Conference. The Wildlife Society, Bethesda, Maryland, USA.

Franklin, A. B., R. J. Gutiérrez, J. D. Nichols, M. E. Seamans, G. C White, G. S. Zimmerman, J. E. Hines, T. E. Munton, W. S. LaHaye, J. A. Blakesley, G. N. Steger, B. R. Noon, D. W. H. Shaw, J. J. Keane, T. L. McDonald, and S. Britting. 2004. Population dynamics of the California spotted owl (Strix occidentalis occidentalis): a meta-analysis. Ornithological Monograph 54:1-54.

Garshelis, D. L., M. L. Gibeau, and S. Herrero. 2005. Grizzly bear demographics in and around Banff National Park and Kananaskis Country, Alberta. Journal of Wildlife Management 69:277-297.

Gibbs, J. P. 2000. Monitoring populations. Pages 213-252 in L. Boitani and T. K. Fuller, editors. Research techniques in animal ecology. Columbia University Press, New York, New York, USA.

Green, G. I., and D. J. Mattson. 2003. Tree rubbing by Yellowstone grizzly bears Ursus arctos. Wildlife Biology 9:1-9.

Harris, R. B. 1984. Preliminary experiments on a scent-station index for grizzly bears. University of Montana, Missoula, USA.

Hines, J. E., and J. D. Nichols. 2002. Investigations of potential bias in the estimation of $\mathrm{k}$ using Pradel's (1996) model for capture-recapture data. Journal of Applied Statistics 29:573-587.

Huggins, R. M. 1991. Some practical aspects of a conditional likelihood approach to capture experiments. Biometrics 47:725-732. 
Joseph, L. N., S. A. Field, C. Wilcox, and H. P. Possingham. 2006. Presence-absence versus abundance data for monitoring threatened species. Conservation Biology 20:1679-1687.

Karamanlidis, A. A., D. Youlatos, S. Sgardelis, and Z. Scouras. 2007. Using sign at power poles to document presence of bears in Greece. Ursus 18:54-61.

Kendall, K. C., J. B. Stetz, J. Boulanger, A. C. Macleod, D. Paetkau, and G. C. White. 2009. Demography and genetic structure of a recovering brown bear population. Journal of Wildlife Management 73:3-17.

Kendall, K. C., J. B. Stetz, D. A. Roon, L. P. Waits, J. B. Boulanger, and D. Paetkau. 2008. Grizzly Bear Density in Glacier National Park, Montana. Journal of Wildlife Management 72:1693-1705.

Kendall, W. L., J. D. Nichols, and J. E. Hines. 1997. Estimating temporary emigration using capture-recapture data with Pollock's robust design. Ecology 78:563-578.

Luikart, G., S. Zundel, D. Rioux, C. Miquel, K. A. Keating, J. T. Hogg, B. Steele, K. Foresman, and P. Taberlet. 2008. Low genotyping error rates and noninvasive sampling in bighorn sheep. Journal of Wildlife Management 72:299-304.

Mace, R. 2005. Interagency population monitoring plan for grizzly bears in the Northern Continental Divide ecosystem, Montana. Montana Department Fish, Wildlife and Parks, Kalispell, USA.

Mace, R., and T. Chilton. 2007. Northern Continental Divide ecosystem grizzly bear monitoring team annual report-2006. Montana Department Fish, Wildlife and Parks, Kalispell, USA.

Mace, R., S. C. Minta, T. L. Manley, and K. E. Aune. 1994. Estimating grizzly bear population size using camera sightings. Wildlife Society Bulletin 22:74-83.

Mace, R., and J. S. Waller. 1998. Demography and population trend of grizzly bears in the Swan Mountains, Montana. Conservation Biology 12:1005-1016.

Nichols, J. D., and J. E. Hines. 2002. Approaches for the direct estimation of $\mathrm{K}$, and demographic contributions to $\mathrm{K}$, using capture-recapture data. Journal of Applied Statistics 29:539-568.

Nichols, J. D., and B. K. Williams. 2006. Monitoring for conservation. Trends in Ecology and Evolution 21:668-673.

Otis, D. L., K. P. Burnham, G. C. White, and D. R. Anderson. 1978. Statistical inference from capture data on closed animal populations. Wildlife Monographs 62.

Paetkau, D. 2003. An empirical exploration of data quality in DNA-based population inventories. Molecular Ecology 12:1375-1387.

Paetkau, D., W. Calvert, I. Stirling, and C. Strobeck. 1995. Microsatellite analysis of population structure in Canadian polar bears. Molecular Ecology 4:347-354.
Pledger, S. 2000. Unified maximum likelihood estimates for closed capturerecapture models using mixtures. Biometrics 56:434-442.

Pollock, K. H., J. D. Nichols, T. R. Simons, G. L. Farnsworth, L. L. Bailey, and J. R. Sauer. 2002. Large scale wildlife monitoring studies: statistical methods for design and analysis. Environmetrics 13:105-119.

Pradel, R. 1996. Utilization of capture-mark-recapture for the study of recruitment and population growth rate. Biometrics 52:703-709.

Proctor, M. F., B. McLellan, and C. Strobeck. 2002. Population fragmentation of grizzly bears in southeastern British Columbia, Canada. Ursus 13:153-160.

Proctor, M. F., B. N. McLellan, C. Strobeck, and R. M. R. Barclay. 2005 Genetic analysis reveals demographic fragmentation of grizzly bears yielding vulnerably small populations. Proceedings of the Royal Society Biology 272:2409-2416.

Roon, D. A., L. P. Waits, and K. C. Kendall. 2005. A simulation test of the effectiveness of several methods for error-checking non-invasive genetic data. Animal Conservation 8:203-215.

Sandercock, B. K., and S. R. Beissinger. 2002. Estimating rates of population change for a neotropical parrot with ratio, mark-recapture and matrix methods. Journal of Applied Statistics 29:589-607.

Schwartz, M. K., G. Luikart, and R. S. Waples. 2007. Genetic monitoring as a promising tool for conservation and management. Trends in Ecology and Evolution 22:25-33.

Servheen, C., R. Mace, R. Harris, W. Kasworm, W. Wakkinen, B. McLellan, D. Carney, A. Sokkalla, T. Wittinger, J. Waller, F. Hovey, S. Gniadek, K. Kendall, and T. Manley. 1996. Report on methods to determine population size and rate of change for grizzly bears at the ecosystem scale. Report to Interagency Grizzly Bear Committee. U.S Fish and Wildlife Service, Forestry Sciences Lab, Missoula, Montana, USA.

U.S. Fish and Wildlife Service [USFWS]. 1993. Grizzly bear recovery plan. U.S. Fish and Wildlife Service, Missoula, Montana, USA.

White, G. C. 2008. Closed population estimation models and their extensions in Program MARK. Environmental and Ecological Statistics 15:89-99.

White, G. C., and K. P. Burnham. 1999. Program MARK: survival estimation from populations of marked animals. Bird Study Supplement 46:120-138.

Williams, B., J. Nichols, and M. Conroy. 2002. Analysis and management of animal populations. Academic Press, San Diego, California, USA.

Woods, J. G., D. Paetkau, D. Lewis, B. N. McLellan, M. Proctor, and C. Strobeck. 1999. Genetic tagging of free-ranging black and brown bears. Wildlife Society Bulletin 27:616-627.

Associate Editor: White. 